\title{
Case Report: Fever of Unknown Origin -An Unusual Presentation for Diffuse Large B-Cell Lymphoma
}

\author{
Chidinma Onweni ${ }^{1}$, Jennifer Treece ${ }^{1}$, Christine Moore ${ }^{1}$, Mailien Rogers ${ }^{2}$ \\ ${ }^{1}$ Department of Internal Medicine, East Tennessee State University, Johnson City, TN, USA \\ ${ }^{2}$ Department of Hematology and Oncology, James Quillen Veterans Affairs, Mountain Home, TN, USA \\ Email: drmailien@gmail.com
}

How to cite this paper: Onweni, C., Treece, J., Moore, C. and Rogers, M. (2017) Case Report: Fever of Unknown OriginAn Unusual Presentation for Diffuse Large B-Cell Lymphoma. Journal of Cancer Therapy, 8, 405-412.

https://doi.org/10.4236/jct.2017.84035

Received: April 1, 2017

Accepted: April 27, 2017

Published: April 30, 2017

Copyright $\odot 2017$ by authors and Scientific Research Publishing Inc. This work is licensed under the Creative Commons Attribution International License (CC BY 4.0).

http://creativecommons.org/licenses/by/4.0/

\begin{abstract}
A 61-year-old male initially presented with fever of unknown origin. He had extensive work-up over two years including an infectious diseases panel, autoimmune studies, and Rheumatology and Hematology evaluations. The patient was initially diagnosed with Adult Still's disease and underwent an outpatient right nodal fine-needle aspiration that was indeterminate. After continued failure of treatment for Adult Still's disease, the patient had surgical resection of a right axillary lymph node that yielded the diagnosis of diffuse large B-cell lymphoma. Further work-up revealed Epstein-Barr virus positivity, the possible trigger behind his mutation for diffuse large B-cell lymphoma and its uncommon presentation. The patient met criteria for central nervous system prophylaxis and received multiple administrations throughout his therapy. He ultimately expired following recurrence of his disease at its initial site but without central nervous system involvement. We report an uncommon presentation of a patient with diffuse large B-cell lymphoma. This lymphoma can have numerous, vague presentations requiring a broad differential diagnosis and may lead to multiple evaluations prior to an ultimate diagnosis. We will also discuss the need for central nervous system prophylaxis, how this patient is qualified for prophylaxis, and how central nervous system prophylaxis benefits, harms, or does not affect patients with diffuse large B-cell lymphoma.
\end{abstract}

\section{Keywords}

Fever of Unknown Origin, Epstein-Barr Virus, Diffuse Large B-Cell Lymphoma, Non-Hodgkin's Lymphoma

\section{Introduction}

Non-Hodgkin's lymphomas (NHL) are a heterogeneous group of lymphoproli- 
ferative disorders originating in B-lymphocytes, T-lymphocytes, and natural killer cells. It is the seventh leading cause of new cancer cases. The causes of NHL are divided into four groups: immune suppression (primary or secondary), infectious agent (i.e. human immunodeficiency virus, Epstein-Barr virus, human herpes virus-8), toxin exposure (i.e. Agent Orange), and familial [1].

Diffuse large B-cell lymphoma (DLBCL) is the most common type of NHL, accounting for approximately $30 \%$ of all cases [2]. The typical presentation is a rapidly enlarging symptomatic mass from lymph nodal enlargement usually in the neck, abdomen, or mediastinum (ex. primary mediastinal large B-cell lymphoma), but it can present anywhere in the body including bone marrow and gastrointestinal tract [3]. Systemic "B" symptoms (fever, weight loss $\geq 10 \%$ body weight over 6 months, and drenching night sweats) are observed in approximately $30 \%$ of patients [4]. Serum lactate dehydrogenase (LDH) is elevated in over one-half of patients. The diagnosis of DLBCL is best made from excisional tissue biopsy, most commonly a biopsy of a lymph node. Some patients do not present with overt lymphadenopathy and require the pathologic evaluation of another tissue such as pleural fluid or spleen for diagnosis [5].

Of note, the patient in this case report did not present with lymphadenopathy or any palpable mass. His only complaints were intermittent high-grade fever, cough, and severe fatigue after exposure to insects.

\section{Case Report}

Mr. C. was a 61-year-old male who initially presented in 2014 with fever of unknown origin (FUO). His high-grade fever was intermittent and accompanied by cough and fatigue after remote "tick and chigger" bites. Past medical history included coronary artery disease, Barrett's esophagus, benign prostatic hypertrophy and osteoarthritis. Family history was remarkable for paternal lung cancer and maternal rheumatoid arthritis. He served in the Army and denied use of tobacco, alcohol or illicit drugs. The patient's full work-up for FUO included a chest $\mathrm{x}$-ray, urinalysis, and blood cultures, all of which were negative. Additional hematologic studies including glycophosphatidylinositol (GPI) anchor markers and Coomb's test were negative. Anti-histone antibodies were weakly positive. Infectious Disease (ID) was consulted for insect bites. Flow cytometry was initially completed as the patient had monocytosis, and this was non-specific. ID evaluated the patient, and no infectious etiology was found. The patient was initially started on doxycycline and steroids by ID, and the patient experienced transient clinical improvement. At that time, his erythrocyte sedimentation rate (ESR) was elevated, C-reactive protein (CRP) was normal, and antinuclear antibody (ANA) was positive at 1:160, which decreased to 1:80 after steroids were initiated.

Mr. C. continued to have high-grade fevers and chest discomfort despite treatment. Computerized tomography (CT) revealed hepatosplenomegaly and very mild periportal and celiac adenopathy. The Interventional Radiology (IR) team reviewed scans but were not convinced at that time that there was a tissue 
to biopsy that would be diagnostic. Hematology and Oncology was re-consulted for the patient for further evaluation. Flow cytometry, peripheral blood smear, and bone marrow biopsy were negative. Rheumatology evaluated the patient gave the diagnosis of Adult Still's disease (ASD); however, he did not show significant improvement while on prednisone therapy. The patient was sent for a second Rheumatology opinion and had a fine-needle aspiration (FNA) of a left axillary lymph node, which was non-diagnostic.

Over the course of a year, the patient had repeated lymph node FNA that were inconclusive and continued to be treated for ASD with steroids despite lack of clinical improvement. Therefore, the patient underwent surgical resection of a right axillary lymph node, which was diagnostic for diffuse large B-cell lymphoma (DLBCL). Bone marrow aspirate and biopsy of left posterior iliac crest were negative. Excisional biopsy of left axillary lymph node and right subcervical lymph node were also negative. Additional testing revealed Epstein-Barr virus positivity, the hypothesized mutation behind his DLBCL.

Following lymph node biopsy that was diagnostic for DLBCL, the patient became jaundiced with elevated total bilirubin and direct bilirubin, developed abdominal distention, continued to experience worsening fever and chest discomfort, and developed diffuse edema. The patient became hypoxic, requiring supplemental oxygen. He was hospitalized for further work-up. A repeat bone marrow biopsy was performed as well as a lumbar puncture (LP) for cerebrospinal fluid (CSF) evaluation. The patient also had an MRI performed and port placed. The patient's repeat bone marrow biopsy and LP for CSF evaluation were both negative for involvement of DLBCL.

During his stay, the liver enzymes and bilirubin continued to worsen with clinical decompensation; he was started on the R-CHOP (rituximab, cyclophosphamide, doxorubicin, vincristine, and prednisone) chemotherapy for treatment of DLBCL. Cyclophosphamide, doxorubicin, and vincristine were held due to the patient's hyperbilirubinemia, only rituximab and high-dose prednisone were used for the five day treatment cycle. The patient experienced tumorlysis syndrome with elevated uric acid and phosphorus. He was treated with IV fluid, rasburicase, and aluminum hydroxide suspension. During cycle 1 day 1 , the patient experienced rigors and fever during the administration of rituximab when the rate was up to $150 \mathrm{~mL} / \mathrm{hr}$; the patient was given meperidine and promethazine, rituximab was resumed at a slower rate of $100 \mathrm{~mL} / \mathrm{hr}$ until completed. Within a few hours, the patient's fever abated and bilirubin started decreasing but uric acid level was $>1$ and phosphorus and potassium remained elevated, consistent with tumor lysis syndrome. The patient was given $9 \mathrm{mg}$ of rasburicase and started on bicarbonate drip. He was observed for several days before discharging to home.

Following hospital discharge, the patient's care was transferred to an oncologist closer to the patient's home. The goal of treatment was curative, and R$\mathrm{CHOP}$ and prophylactic intrathecal treatment were recommended to the accepting oncologist. Although the patient was high risk for central nervous system 
(CNS) involvement despite negative CSF studies and normal MRI, the patient received four cycles of prophylactic intracranial chemotherapy. He went into remission for several months following 8 total cycles of R-CHOP until reactivation of his DLBCL at its initial site with no CNS involvement. It did not respond to one cycle of RICE (rituximab, ifosphamide, carboplatinum, etoposide) and the patient expired shortly after.

\section{Discussion}

Diffuse large B-cell lymphoma (DLBCL), the most common form of Non- Hodgkin's lymphoma (NHL), can have multiple presentations. The purpose of this case report is to make the medical community aware of the odd presentations associated with DLBCL. The most common presentation is persistent fever with lymphadenopathy, but the patient in this case report did not have lymphadenopathy and only had a persistent fever, which made his diagnosis challenging. This patient also had many negative tissue samples from bone marrow biopsy and lymph node fine needle aspiration (FNA). An excisional lymph node biopsy is recommended to establish the diagnosis of NHL since classification is determined from its immunophenotype and morphology. FNA alone is not acceptable as the diagnostic tool for NHL [6]. This may explain why our patient's diagnosis was missed initially by FNA, which delayed his treatment. In addition, patients with infectious causes of NHL can present atypically [7]. Our patient was positive for Epstein-Barr virus, the likely mutation associated with his DL-BCL [7].

Another objective of this case report is to discuss the decision for intrathecal central nervous system (CNS) prophylaxis in patients with NHL. Relapse to the CNS in patients with aggressive NHL is a serious complication with poor prognosis. Its prevalence is $4 \%$ to $30 \%$, depending on the histology and stage of the lymphoma [8].

In the subset of aggressive NHL represented by diffuse large B-cell lymphoma (DLBCL), there is no clear consensus as to which patients benefit from CNS prophylaxis [9]. The rate of relapse to the CNS in patients with DLBCL is reported to be $4 \%$ to $27 \%$ [10]. Based on multiple retrospective studies, criteria for those with DLBCL that should receive CNS prophylaxis were developed based on risk factors. Risk factors for CNS relapse in DLBCL include the site of lymphoma involvement (i.e., bone marrow, testicular, or paranasal sinus involvement), clinical parameters (i.e., age), and labs (i.e., lactate dehydrogenase $(\mathrm{LDH}))[11]$.

The patient in this case study was determined to be high risk for CNS involvement due to his age $>60$ years, elevated LDH $>10,000 \mathrm{U} / \mathrm{L}$, stage III disease, and involvement of the liver and spleen. The patient's MRI of the brain was negative without enhancing or suspicious lesions. According to the International Prognostic Index, the patient in this case report had a score of 4 on initial diagnosis for DLBCL and was determined to be high risk for CNS involvement and therefore qualified for CNS prophylaxis (Table 1) [12].

Per the Prognostic Model to Assess the Risk of CNS Disease from National 
Comprehensive Cancer Network (NCCN), the patient in this case report had a score was 5 on initial diagnosis and was therefore high risk for CNS involvement and qualified for prophylactic intracranial chemotherapy, which the patient received (Table 2) [13].

The patient in the case report did not develop CNS lymphoma despite being high risk per the International Prognostic Index for Aggressive Lymphoma and the Prognostic Model to Assess the Risk of CNS Disease from NCCN [12] [13]. This may have been secondary to receiving intracranial prophylaxis or due to DLBCL having lower risk of CNS involvement than other NHLs [10]. The patient underwent prophylactic intracranial chemotherapy but had recurrence of his lymphoma in his liver and spleen (Figure 1), as well as the lymph nodes of his mediastinum (Figure 2), retroperitoneum (Figure 3), and porta hepatic lymph nodes. CT of the head at the time of the recurrence was negative suggesting no CNS involvement.

\section{Conclusion}

Diffuse large B-cell lymphoma (DLBCL) can have different presentations, which may lead to extensive medical and surgical evaluations with delayed diagnosis and treatment. There are new categories of DLBCL, defined by extra-nodal primary sites and the association with viruses such as Epstein-Barr virus (EBV) or human herpes virus-8 (HHV-8). There was concern that the patient in this case

Table 1. The International Prognostic Index for Aggressive Lymphoma.

\begin{tabular}{cc}
\hline Clinical Risk Factor & Point per Risk Factor \\
\hline Age $>60$ & 1 \\
serum LDH $>$ normal & 1 \\
performance status $2-4$ & 1 \\
stage 3 or 4 & 1 \\
extra nodal involvement $>1$ & 1 \\
\hline
\end{tabular}

Risk for CNS involvement based on total points: 0 - 1 points is low risk, 2 points is low to intermediate risk, 3 points is intermediate to high risk, and 4 or 5 points is high risk.

Table 2. Prognostic Model to Assess the Risk of CNS Disease from National Comprehensive Cancer Network (NCCN).

\begin{tabular}{cc}
\hline Clinical Risk Factor & Point per Risk Factor \\
\hline Age $>60$ & 1 \\
Serum LDH $>$ normal & 1 \\
Performance status $>1$ & 1 \\
Stage 3 or 4 & 1 \\
Extra nodal involvement $>1$ & 1 \\
Kidney or adrenal gland involvement & 1 \\
\hline
\end{tabular}

Risk for CNS involvement based on total points: 0 - 1 points is low risk, 2 - 3 points is intermediate risk, and $4-6$ points is high risk. 


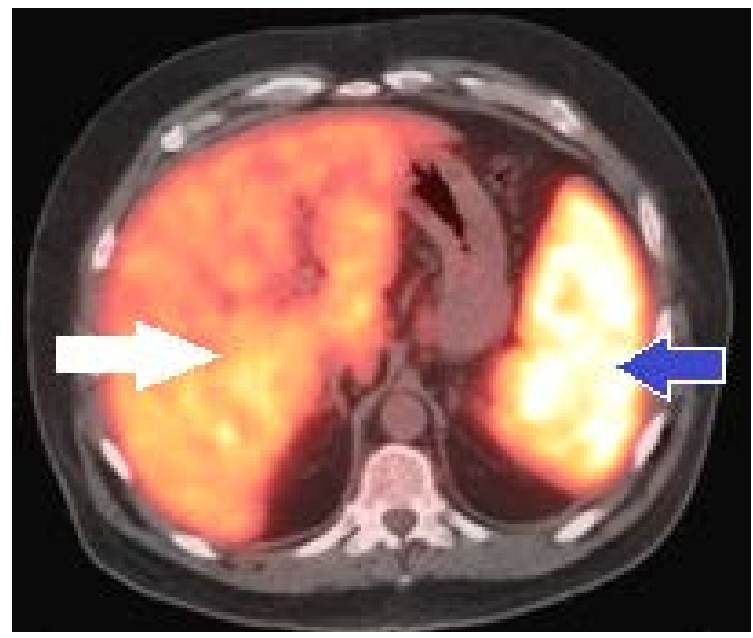

Figure 1. PET/CT of head/thorax: blue arrow-diffusely enlarged spleen with SUV of 17.7, white arrow-diffusely enlarged liver with SUV of 8 .

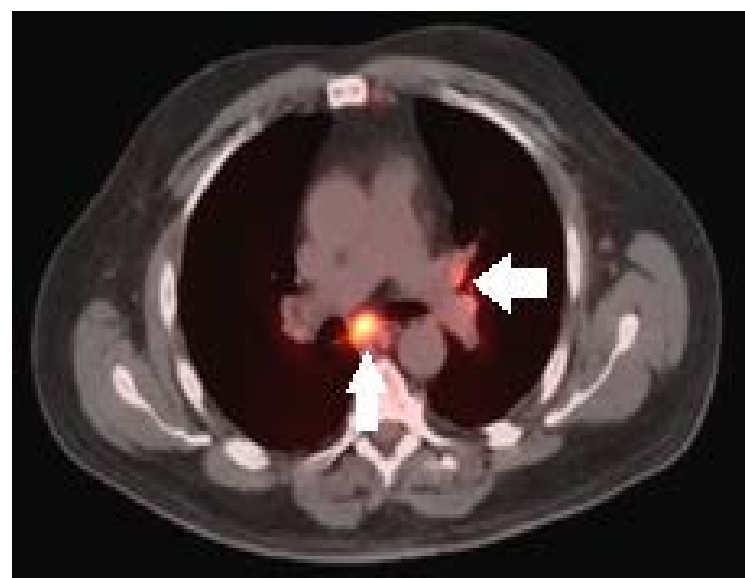

Figure 2. PET/CT of head/thorax: malignancy within mediastinal lymph node basin; right arrowindicates left hilar lymph nodes, bottom arrow indicates subcarinal lymph node.

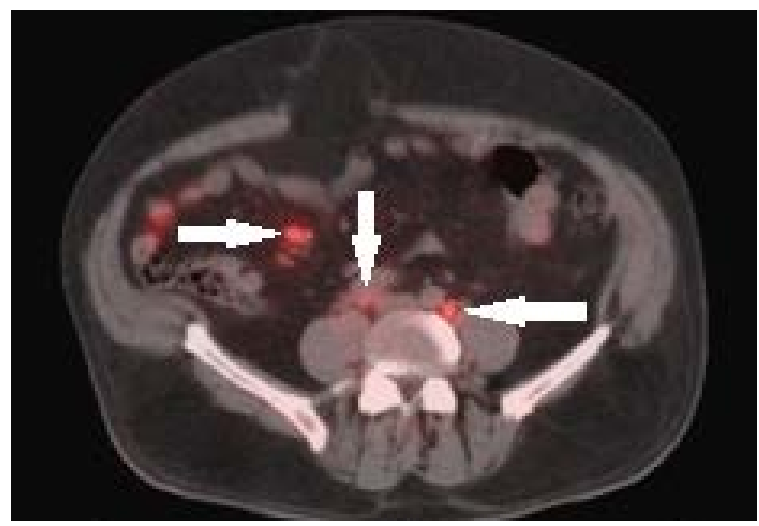

Figure 3. PET/CT of head/thorax: arrows indicate retroperitoneal spread of malignancy along pericaval, aortocaval and periaortic nodal tissue, respectively. 
report may have had an EBV triggered mutation for DLBCL, which may have caused this patient to have an unusual presentation. The patient also met criteria for CNS prophylaxis, which he received. Because the patient expired, the efficacy of the intrathecal chemoprophylaxis can only be inferred: although the patient's disease recurred and was ultimately fatal, it was not detected in CNS.

\section{References}

[1] Hagop (2016) MD Anderson Manual of Medical Oncology. McGraw-Hill Education, Hong Kong.

[2] Swerdlow, S.H. (2008) World Health Organization of Tumors of Haematopoeitic and Lymphoid Tissues. IARC Press, Lyon.

[3] Moller, M.B., Pedersen, N.T. and Christensen, B.E. (2004) Diffuse Large B-Cell Lymphoma: Clinical Implications of Extranodal versus Nodal Presentation-A Population-Based Study of 1575 Cases. British Journal of Haematology, 124, 151. https://doi.org/10.1046/j.1365-2141.2003.04749.x

[4] Armitage, J.O. and Weisenburger, D.D. (1998) New Approach to Classifying NonHodgkin's Lymphomas: Clinical Features of the Major Histologic Subtypes. Non-Hodgkin's Lymphoma Classification Project. Journal of Clinical Oncology, 16, 2780. https://doi.org/10.1200/JCO.1998.16.8.2780

[5] Roschewski, M., Staudt, L.M. and Wilson, W.H. (2014) Diffuse Large B-Cell Lymphoma-Treatment Approaches in the Molecular Era. Nature Reviews. Clinical Oncology, 11, 12-23. https://doi.org/10.1038/nrclinonc.2013.197

[6] Oh, E.J., Hong, S.W., Jeong, H.J. and Yoon, S.O. (2014) The Diagnostic Approach to Fine-Needle Aspiration of Malignant Lymphoma: Using Cytomorphology and Immunocytochemistry with Cell Transfer Method. Diagnostic Cytopathology, 42, 671-679. https://doi.org/10.1002/dc.23110

[7] Song, C.G., Huang, J.J., Li, Y.J., Xia, Y., Wang, Y., Bi, X.W., Jiang W.Q., Huang, H.Q., Lin, T.Y. and Li, Z.M. (2015) Epstein-Barr Virus-Positive Diffuse Large B-Cell Lymphoma in the Elderly: A Matched Case-Control Analysis. PLoS ONE, 29, 7. https://doi.org/10.1371/journal.pone.0133973

[8] Van Besien, K., Ha, C.S., Murphy, S., McLaughlin, P., Rodriguez, A., Amin, K., Forman, A., Romaguera, J., Hagemeister, F., Bachier, C., Sarris, A., Sobocinski, K.S., Cox, J.D. and Cabanillas, F. (1998) Risk Factors, Treatment, and Outcome of Central Nervous System Recurrence in Adults with Intermediate-Grade and Immunoblastic Lymphoma. Blood, 91, 1178.

[9] Arkenau, H.T., Chong, G., Cunningham, D., Watkins, D., Agarwal, R., Sirohi, B., Trumper, M., Norman, A., Wotherspoon, A. and Horwich, A. (2007) The Role of Intrathecal Chemotherapy Prophylaxis in Patients with Diffuse Large B-Cell Lymphoma. Annals of Oncology, 18, 541-545. https://doi.org/10.1093/annonc/mdl434

[10] Kridel, R. and Dietrich, P.Y. (2011) Prevention of CNS Relapse in Diffuse Large B-Cell Lymphoma. The Lancet Oncology, 12, 1258-1266.

[11] Herman, T.S., Hammond N., Jones, S.E., et al. (1979) Involvement of the Central Nervous System by Non-Hodgkin's Lymphoma: Southwest Oncology Group Experience. Cancer, 43, 390-397.

https://doi.org/10.1002/1097-0142(197901)43:1<390::AID-CNCR2820430155>3.0.C $\underline{\mathrm{O} ; 2-\mathrm{U}}$

[12] The International Non-Hodgkin's Lymphoma Prognostic Factors Project (1993) A Predictive Model for Aggressive Non-Hodgkin's Lymphoma. New England Journal 
of Medicine, 329, 987-994. https://doi.org/10.1056/NEJM199309303291402

[13] National Comprehensive Cancer Network (2016) Non-Hodgkin's Lymphoma. National Comprehensive Cancer Network. Fort Washington.

Submit or recommend next manuscript to SCIRP and we will provide best service for you:

Accepting pre-submission inquiries through Email, Facebook, LinkedIn, Twitter, etc. A wide selection of journals (inclusive of 9 subjects, more than 200 journals)

Providing 24-hour high-quality service

User-friendly online submission system

Fair and swift peer-review system

Efficient typesetting and proofreading procedure

Display of the result of downloads and visits, as well as the number of cited articles Maximum dissemination of your research work

Submit your manuscript at: http://papersubmission.scirp.org/

Or contact jct@scirp.org 